\title{
O POEMA LAMBE A ESPINHA: POESIA E FOTOGRAFIAS NO CADERNO DAS INVIABILIDADES, DE ELISA CAETANO E LAÍS BLANCO
}

\author{
Renan Augusto Ferreira Bolognin \\ Doutorando em Estudos Literários pelo PPGEL da Unesp/Araraquara \\ renanbolognin@hotmail.com
}

O caderno das inviabilidades (2016), escrito por Eliza Caetano e com fotografias de Laís Blanco, denota a inexequibilidade da tradução do poético a um corpo, seja o humano, seja outro suporte que o contenha. Em outras palavras, é uma "poética do limiar", alegoria do que não pode ser traduzido em qualquer corpo ou suporte. Em relação à localização desta poética, ela está no inexequível, intransitável, intraduzível da fatura poética e seu(s) elemento(s) transbordando a escrita do papel e derramando resquícios não materializados e não depreendidos como a pedra de toque dos poemas e dos cliques de suas fotografias.

Similar a isso, lembramos Jacques Rancière (1995, p. 141-142) e suas considerações estético-políticas n“A voz e o corpo", a respeito dos textos de Rimbaud voltados à exegese da letra pelo corpo: "A chave de um texto é, comumente, um corpo. Achar um corpo debaixo de letras, em letras". Por isso, digamos que a poeticidade deste livro está, de certa forma, localizada no território inacessível do poético.

No primeiro poema do livro intitulado *: "O corpo do poema desenhado em meu corpo, estendido, sunbathing sobre a minha anca esquerda. Não sei se esqueço o corpo do seu poema. O poema em branco me lambendo a espinha" (CAETANO; BLANCO, 2016, p. 15) corpos poéticos são delineados e direcionados aos da/do eu-lírica/lírico que parecem revelar 
algo faltante e incômodo em seus interstícios. Lambendo a espinha. Essa impossibilidade reside na não aderência do outro no eu-poético, que as/os deixa também separadas/os poeticamente, inacessíveis: corpórea e poeticamente localizadas no receio do que lembrar e do que esquecer.

Posto isso, vale à pena recorrer ao dicionário e buscar acepções para inviável, ou como diz o primeiro verso de um poema homônimo ao livro: "Minha vontade irremediável de listar palavras inviáveis" (idem, p.33):

1.Que não pode ser percorrido ou acedido = INACESSÍVEL, INTRANSITÁVEL;

2.Que não pode ser feito ou executado = INEXEQUÍVEL $\neq$ EXEQUÍVEL;

3.Que não tem condições para durar ou sobreviver.

Aliado às acepções acima referidas, pensemos no título do livro: $O$ caderno das inviabilidades. A primeira das inviabilidades é um questionamento em torno do livro/suporte/meio traçar uma relação frutífera entre texto poético e fotografias. Quer dizer, a tentativa de um poético no qual os significados se encontram no limiar das duas artes, não na relação. Em sua dessemelhança, não igualdade. Os significados dos poemas deste livro parecem resultar mais da subtração de texto e fotografias do que de sua soma.

Seguida a esta subtração de meios estéticos, vemo-nos face a poemas próximos a esboços (afinal de contas eles fazem parte de um caderno). Talvez por isso, encontremos vários poemas intitulados *, além de uma sequência de três poemas tentativas (primeira tentativa, segunda tentativa e terceira tentativa das ps. 23 a 28) como modelares da ingrata tarefa de mediação da/do poeta a um corpo “Entenda:/ a vírgula reverbera/o hiato dos olhos" (idem, p. 23), do poético reverberando no limiar de poemas e fotos "[...] dentro de mim é como o centro da cidade resmungando bobagem, lixo, barulho, palavras, gente e a 
espera impaciente pelo silêncio do fim do dia" (ibidem, p. 25) e análogos à impossibilidade de mediação da interioridade por palavras, bem como de seu exterior "Paro, sento, teço e o/ tecido não me cobre" (ibidem, p. 27).

Uma poética, por essa razão, decididamente emperrada: este é um caderno de poemas executados no inexequível. Nascimento corpóreo da poesia do inefável, do que não estabelece pontos específicos do poético, como no poema "Pontos cardinais" (ibidem, p. 17): "se eu te disser quem sou, sou em círculos [...]/ calculo os passos para não pisar em linhas/ procuro seguir mas dou voltas no quarteirão/ se eu te disser quem sou/os pontos cardinais trocarão de lugar". A propósito, pontos trocando de lugar e não encontrando uma corporeidade viável para estabelecer-se, são as construções poéticas mais recorrentes “Insisto./ Paro, sento, teço/ Faço rosas, faço ventos, cubro-me/ Tranço linhas confusas e frias./ É por nada" (ibidem, p. 27), sobre a impossibilidade do significado poético pisar em terra firme: ele é desestabilizado pela ambiguidade e obscurantismo das metáforas poéticas à moda dos autores/poemas do período moderno estudados por Hugo Friedrich (1978). Devido à incongruência do poema (significante) com seu significado, este livro também serve como exercício pedagógico (pois é também um caderno) sobre as diferenças de significados trazidas por uns e outros leitores de cada poema “[...] carrego então/ num lugar estranho/ promessas que perderam sua data de validade e senso de direção/ a promessa sua, continua sendo noutro país/ esse fardo que você ignora e que eu demoro em a largar (ibidem, p. 29)".

A partir da página 35 dO caderno das inviabilidades, acompanhamos 15 fotografias além de outras duas em cada contracapa do livro (caderno) - entrelaçadas ao significado geral dos poemas da 1 a parte do caderno, apresentando paisagens (ibidem, ps. $35,39,41$, 57, 59), objetos de difícil compreensão (ibidem, ps. $37,43,45,47,49,55$ ) e pessoas (ibidem, 
ps. 50 e $51 ; 61)$, etc. Estas são algumas das categorias possíveis para pensar como as fotografias do livro engendram inviabilidades de significados. Sua riqueza advém de sua subtração para serem pensadas como performance artística tal qual Charlotte Cotton (2010, p. 21-47) propôs ao analisar o tratamento dado à fotografia antes de ser tirada por artistas contemporâneos do quilate de Sophie Calle, Zhang Huan, Erwin Wurm, Gillian Wearing, Bettina von Zwehl, Shizuka Yokomizo, Hellen van Meene, Roy Villevoye, Nia Katchadourian, Tim Davis e Roni Horn. Dessa maneira, quando as fotografias são pensadas de antemão como parecem as fotografias realizadas por Laís Blanco - põem em questionamento a relação umbilical do representado com seus significados de maneira performática. Em outras palavras, o poético, das letras, lambe a espinha de outro corpo e oculta o sentido ao qual essas fotografias foram preparadas pela/o artista.

Outras obras literárias que trazem a relação com a fotografia como recordação após a leitura dO caderno das inviabilidades são Nadja, de André Bréton, e Paranoia, de Roberto Piva. Primeiramente, ambos os livros possuem correlações surreais estreitas com o representado em cada fotografia. No livro de Bréton, há algumas fotografias que parecem temas retomados nas fotografas de Laís Blanco como objetos que extrapolam sua função/existência no mundo real através da representação fotográfica. Já o livro de Piva tece possíveis influências estilísticas na escrita de Eliza Caetano (guardadas as devidas proporções) pelo caráter inefável e, por vezes, labiríntico das metáforas dos livros dos dois últimos autores.

Da página 63 em diante, as inviabilidades dos poemas parecem mudar de tom ao enfatizar-se a inexatidão do que é ser mulher no poema "Idade cronológica": "Tenho medos de menina/olhos de menina/peitos de menina/durmo com a luz acesa/ [...] e faço festas no 
chuveiro" (CAETANO; BLANCO, 2016, p. 63) e colocar neste primeiro poema da (que chamamos) segunda parte (do livro) questões relacionadas à infância, à sexualidade e à idade (irresoluta) como centrais e inviáveis de serem postas no papel. Isso também pode ser interpretado em outro poema intitulado * (Dizem que sou elegante): Não se engane com a foto aérea. As raízes ficam debaixo da terra, rompem o concreto e invadem os bueiros [...] Além dos bueiros, há o homem que me despe depois de um dia de trabalho, que não conhece a elegância e aposta no que não vê (idem, p. 83).

Por fim, também merece destaque neste livro primoroso uma (possível leitura de) aproximação à escrita do branco da página, que interessa tanto à Jacques Derrida (1997) "não sei se esqueço/ o desenho do corpo do poema/no meu corpo/ sua língua branca sobre a minha espinha" (CAETANO; BLANCO, 2016, p. 95), como responsável por delinear uma proposta a nós, leitores, de sermos este branco da página e inviabilizarmos significados fixos nas letras negras das páginas d'O caderno das inviabilidades.

\section{REFERÊNCIAS}

BAUDRILLARD, Jean. Simulacros e simulação. Trad. Maria João da Costa Pereira. Lisboa: Relógio d'Água, 1991 (1981).

BRÉTON, André. Nadja. Trad. Ivo Barroso. São Paulo: Cosac Naify, 2007 (1928)

CAETANO, Eliza; BLANCO, Laís. O caderno das inviabilidades. Bragança Paulista, SP: Urutau, 2016.

COTTON, Charlotte. Se isto é arte. In: . A fotografia como arte contemporânea. Trad. Maria Silvia Mourão Netto. São Paulo: Editora WMF Martins Fontes, 2010, p. 21-47.

DERRIDA, Jacques. La doble sesión. In: La diseminación. 7ed. Trad. José Martin Arancibia. Madrid, España: Omagraf, 1997 (1972), p. 263-340.

FRIEDRICH, Hugo. Estrutura da lírica moderna: da metade do século XIX a meados do século XX. Trad.Marise M. Curioni; Dora F. da Silva. São Paulo: Duas cidades, 1978 (1956). 
INVIÁVEL. Dicionário Priberam da Língua Portuguesa [em linha], 2008-2013. Disponível em: <https://www.priberam.pt/dlpo/invi\%C3\%A1vel>. Acesso em: 30/Out/2017.

PIVA, Roberto; LEE, Wesley Duke. Paranoia. 2ed. São Paulo: Instituto Moreira Salles; Jacarandá, 2000 (1963).

RANCIÈRE, Jacques. Políticas da escrita. Trad. Raquel Ramalhete [et al]. Rio de Janeiro: Ed. 34, 1995.

Resenha recebida em: 20 de maio de 2018. Resenha aprovada em: 06 de agosto de 2018. 